\title{
LA DRAMATURGIA DE LOS GLÁSICOS COMO INSPIRACIÓN CINEMATOGRÁFICA
}

\author{
Guillermo HERAS
}

En primer lugar, me ha parecido más interesante utilizar el término dramaturgia, fundamentalmente en su concepción alemana, para intentar desgranar algunas reflexiones sobre la continua relación del cine con los textos teatrales clásicos, ya sean estos de los maestros griegos, las obras del Siglo de Oro y el Teatro Isabelino, los seguidores del Romanticismo hasta llegar a los realistas de comienzos del siglo XX donde sin duda, y dada la gran producción novelística de esta época, han sido muchas las versiones pasadas de la literatura a la pantalla. En suma, el cinematógrafo que nació como diversión y con una expresión de imágenes mudas tardó un tanto en buscar ciertas obras literarias, como las de Dumas o Verne, para al llegar el sonoro nutrirse de las grandes historias de esos narradores de finales del siglo XIX y comienzos del XX. La dramaturgia escénica, en su concepción contemporánea, alude a la lectura específica o punto de vista que el director, ayudado por el dramaturgo, quiere proponer de un texto concreto y, como tal, también polisémico y abierto a todo tipo de interpretaciones artísticas e ideológicas.

No obstante, y por una cuestión de espacio me limitaré a intentar señalar algunas cuestiones más relacionadas con el periodo de la Grecia Clásica y la autoría del siglo XVII, tanto en España como Inglaterra, en su relación con la práctica cinematográfica y, como he señalado, basándome en las obras dramáticas que ejercieron de inspiración a los directores cinematográficos.

Empezaré por el territorio más cercano, el de nuestra gran dramaturgia del Siglo de Oro que, curiosamente, apenas ha tenido presencia significante en nuestra filmografía nacional y, mucho menos, en la internacional. Planteo esa curiosidad por el hecho cierto que con la manipulación ejercida por el franquismo y sus ideólogos sobre nuestro teatro del siglo XVII, apelando al tema trillado del honor y los valores patrios $y$, tomando como base determinados títulos que continuamente se representaron en los casposos escenarios de la Dictadura, ese hecho apenas tuvo relación directa para que la industria cinematográfica del Régimen hiciera demasiadas incursiones en ese repertorio, lo que dice mucho de la incultura general de las élites culturales de esos facciosos próceres.

De la época del cine mudo existe una adaptación de El alcalde de Zalamea, en 1914, dirigida por Juan Solé Mestres y en la que actúa uno de los intelectuales destacados del teatro de esa época, Adriá Gual. Se conoce también una versión de Don Juan Tenorio del 
año 1908, de Ricardo Baños, que luego volvió a rodar en 1922. Como curiosidad, parece que de esa época, existe una versión porno muy apreciada por el monarca de entonces.

Ya entre la postguerra y el tardo franquismo, se pueden destacar: Fuenteovejuna (1947) de Antonio Román, y luego la versión del mismo título que hizo en 1970 Juan Guerrero Zamora o El Alcalde de Zalamea (1954) de José Gutiérrez Maesso.

En 1973, Rafael Gil rueda El mejor alcalde el Rey y, en 1972, Mario Camus filma La leyenda del alcalde de Zalamea con Paco Rabal, Fernán Gómez y Charo López en el reparto. Tomando la referencia de La vida es sueño, de Calderón, Luis Lucia dirige El príncipe encadenado, con un reparto en el que figuran Pedro Osinaga y Katia Loritz, algo que por lo menos resulta un tanto exótico. En 1996, César Fernández Ardavin rueda La Celestina.

Como curiosidades existen también algunas versiones latinoamericanas de nuestros clásicos, como son La casada casa quiere (1948), de Calderón, dirigida por el mexicano Gilberto Martínez Solares y en Argentina Luis Saslavsky filma La dama duende con guion adaptado por Rafael Alberti y María Teresa León.

Más recientes son El perro del hortelano (1996), con la excelente dirección de Pilar Miró, y la nueva versión de La Celestina dirigida por Gerardo Vera en 1996, con Penélope Cruz y Juan Diego Botto.

Como algo extremadamente exótico, el interesante realizador chileno Raoul Ruiz, rodó en Francia en 1986, Memoire des apparences, una versión muy libre de La vida es sueño.

Todo esto, si lo comparamos con las películas que se han filmado a lo largo del tiempo sobre obras de autores del periodo isabelino, incluyendo, claro está, la sobreabundancia de títulos de Shakespeare, resulta, como ya he dicho bastante sorprendente. Quizás una de las razones sea que ya con el nacimiento del cine la lengua dominante va a ser el inglés y, por tanto, su repertorio clásico más del gusto de los espectadores dominantes.

Para las referencias históricas tomo como base el libro Introducción a Shakespeare a través del cine, de Fernando Gil Delgado (Ediciones Internacionales Universitarias, Madrid, 2001). El autor nos señala en su prólogo que hasta ese año ha encontrado 392 versiones de la obra teatral de Shakespeare, de las cuales 91 son mudas y el resto en producciones cinematográficas o televisivas. Es evidente que en estos últimos años han surgido nuevos films sobre la dramaturgia del autor y, además podríamos decir que un gran número de producciones que pueden tener su origen en obras míticas del autor, pero que en manos de ciertos cineastas como, por ejemplo, Peter Greeneway, son pretextos para su propia creación. En otros casos, son inspiraciones para musicales como West Side Story, con el fondo de Romeo y Julieta, o El rey León, una mezcla referencial entre la Biblia y Hamlet y, también, la española Los tarantos de 1963 y dirigida por Francisco Rovira Veleta. En films más convencionales aparece, de un modo u otro, el texto dramático de Shakespeare en Laberinto envenenado, basada en Otelo, de Tim Blake Nelson, Romeo debe morir (2000), dirigida por Andrzej Bartkowiak, Trono de sangre (1957), inspirada en Macbeth, de Akira Kurosawa que también rodó Ran (1985), basada en Lear, la película de ciencia-ficción Planeta prohibido (1956) de Fred M.Wilcox, Hamlet va de viaje de negocios (1987) de Aki Kaurismäki, Buscando a Richard (1996), un excelente experimento de Al Pacino, Mi Idaho privado de Gust Van Sant, basada en Enrique IV o Vuelvo a casa de Manoel de Oliveira con el fondo de La tempestad y el afamado Shakespeare in love de John Madden (1998), pero con guion del gran autor Tom Stoppard.

Todas estas películas entrarían de lleno en lo que especificaba como trabajo de dramaturgia de los propios directores a partir de la obra shakespeariana. Lógicamente, 


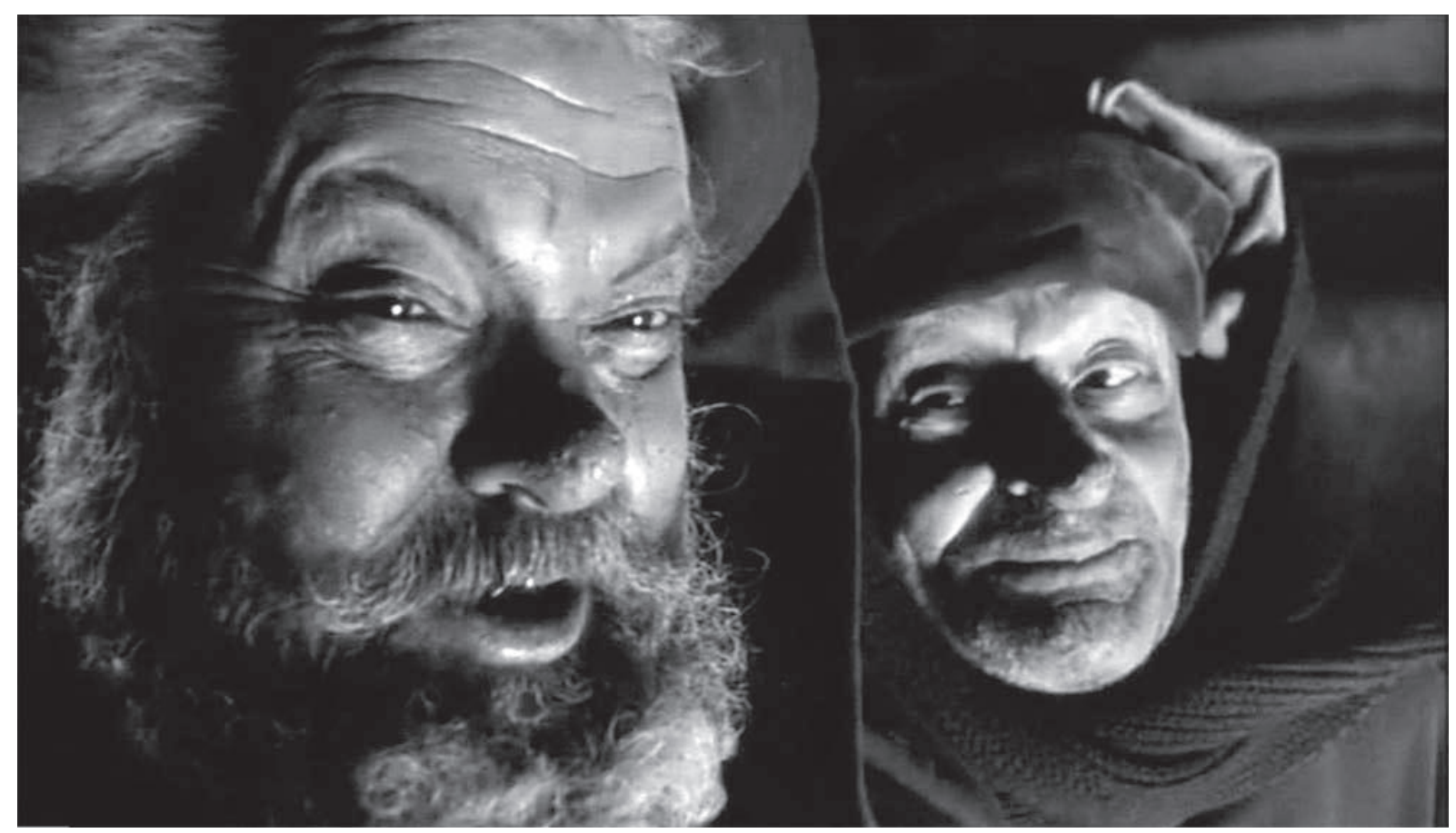

Campanadas a medianoche. Orson Welles

podríamos pensar que, de vivir el Bardo en la actualidad sería uno de los autores literarios más ricos económicamente, gracias a sus derechos de autor. Junto a estos films inspirados en sus argumentos existen otros cientos que siguen más fielmente la estructura teatral y que, sin embargo, son obras maestras del propio cine. Entre la selección más importante, personalmente, elegiría estas cinco:

-Campanadas a medianoche (Falstaff), de Orson Welles (1965).

-El sueño de una noche de verano, de Max Reinhard y William Dieterle (1944).

- Julio César, de Joseph Mankiewicz (1953).

-Rey Lear, de Peter Brook (1969).

-Macbeth, de Orson Welles (1946).

Por supuesto que hay muchas más y no podemos olvidar las direcciones de Kenneth Branagh, Roman Polanski, Laurence Olivier, Grigori Konzintsev, Franco Zefilleri, Trevor Nunn - George Cukor. Significativamente muchos de estos realizadores fueron y son también directores de teatro, por lo que el tránsito de la escena a la pantalla resulta mucho más reconocible que los múltiples experimentos realizados "a partir de la obra original".

Si la presencia del Bardo en los escenarios del mundo no ha dejado de ser fuente constante de la diversidad de miradas que producen sus grandes obras, no podemos extrañarnos de que siempre haya levantado un enorme interés en creadores y productores cinematográficos. Al fin y al cabo, todos los clásicos como ya he dicho, a partir de un cierto momento, están libres de derechos de autor.

En este recorrido por las adaptaciones al cine de los clásicos no podía faltar la referencia al gran teatro de los clásicos griegos, aunque curiosamente tampoco pueden competir en cantidad con las adaptaciones del teatro isabelino.

Si bien ya tenemos muestras fílmicas en adaptaciones del año 1908 de obras como Edipo y Prometeo, o un Edipo Re de 1910 de Giuseppe de Liguoro, la adaptación que 


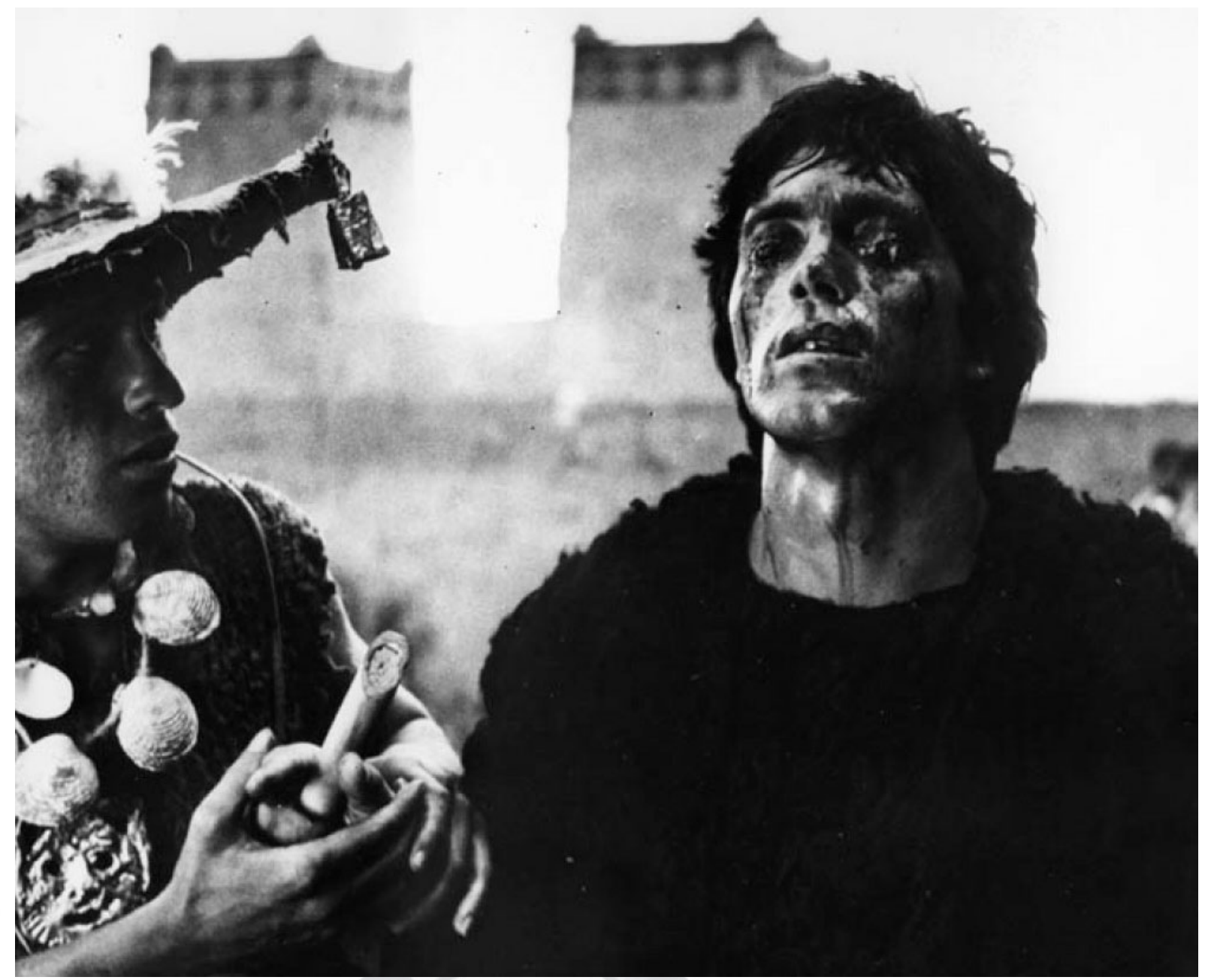

Edipo Rey. Passolini

hizo, en 1991, Theo Frenkel o las interesante incursiones del griego Demetris Gaziadis, casi tenemos que pasar a los años cincuenta para encontrar títulos como Edipo Rey en un famoso director y pedagogo del teatro norteamericano, Tyrone Guthrie, que rueda su versión en 1957. La Antígona de Yorgos Javellas, en 1961, con la gran actriz Irene Papas, en el 1968, Philip Saville con Christopher Plummer, Orson Welles y Lili Palmer en el reparto, la decepcionante Los caníbales (1970) de Liliana Cavani o la extraordinaria experiencia que a partir de la versión de Bertolt Brecht / Hölderling que hicieron los cineastas Jean Marie Straub y Danielle Huillet, rodada en planos estáticos en el marco de las ruinas de Segesta (Sicilia) en el año 1992. También ha sido el trabajo de Michael Cacoyannis el que ha tenido un discurso creativo muy importante sobre los clásicos griegos, bien con sus adaptaciones - bien con películas que contienen la pulsión de esas tragedias. Entre sus títulos Ifigenia (1997), Las troyanas (1971) o Electra (1962).

Pero si hay un cineasta emblemático del siglo XX que supo captar en sus films y en sus obras teatrales toda la fuerza metafórica de la tragedia clásica, ese es, sin duda, Pier Paolo Pasolini. Hombre de cultura todo terreno, transitó por la literatura, el periodismo, la poesía, el teatro y el cine, creando una obra de enorme personalidad y clave para entender una parte del siglo XX. Sus dos obras cinematográficas, por excelencia, basadas en clásicos 
griegos fueron Edipo Rey (1967) con Silvana Mangano y Medea con María Callas (1969), aunque también tiene una película, casi experimental, que tituló Apuntes para una Orestiada africana en 1970.

Como tantos artistas que murieron de manera convulsa y en edad de total madurez, no sabemos hasta donde habría podido llegar Pasolini en sus diversas incursiones en los lenguajes artísticos. Lo que queda claro es cómo en sus películas, tanto en las de inspiración clásica, como en las que abordó temas contemporáneos, la pulsión de la catarsis y la anagnórisis, propia de la tragedia griega, está totalmente presente en su realización. La belleza de las imágenes, la calidad de sus intérpretes, el equilibrio entre tradición y modernidad nos muestran una posible vía de seguir adaptando los clásicos a las pantallas de hoy, aunque estas estén más preocupadas de los shows tecnológicos o las comedias banales. ¿Se acuerdan de ese prodigio de comedia que es To be or not to be, de Ernst Lubisth, rodada nada menos que en 1942 ?

Y ya, para terminar, intentaré hacer algunas reflexiones propias sobre esta relación, siempre intensa. pero también siempre inquietante, entre cine y teatro.

1. Cuando el cine pasó de ser una atracción de barraca de feria a espectáculo de masas, nuevamente se habló de la muerte del teatro, pero pronto se fijan en la representación teatral y sus obras como fuente de inspiración.

2. Muchos de los pioneros, fundamentalmente europeos, que se van incorporando a la industria cinematográfica provienen del teatro, tanto directores, actores como autores.

3. Esa influencia teatral, quizás solo rota por las vanguardias histórica hizo que muchas películas durante una época parecieran teatro filmado.

4. Con las aportaciones de las técnicas de Artaud, Einsestein, Vertof, Kozintsev, Meyerhold, Piscator o Brecht, más las de la nómina de expresionistas alemanes el lenguaje del cine va adquiriendo una especificidad de lenguaje que lo que produce es una influencia decisiva en la puesta en escena teatral, es decir, un claro mestizaje entre ambos lenguajes.

5. De alguna manera ha existido una tendencia, a partir de los años 60, de aspirar a una especie de "sueño eterno" por el que los directores de teatro quieran volcar sus experiencias escénicas como si fueran una película.

6. Definitivamente, toda la dramaturgia contemporánea está atravesada por la influencia del guion cinematográfico y sus diferentes técnicas narrativas.

7. Las puestas en escena actuales deben al concepto de iluminación del cine muchos de sus hallazgos. Por ejemplo, en el modo de crear espacios simbólicos o metafóricos solo a partir de la luz.

8. Las formas de interpretación actoral han caminado paralelas a una estilización continua del modo de encarar la construcción de un personaje.

9. En su relación con los clásicos adaptados a la pantalla podemos hacer una clara referencia a estos temas propuestos:

a) Los clásicos son utilizados en un primer momento como una adaptación simple del tema o personaje del que tratan, sin profundizar en el lenguaje específico del film.

b) Con el tiempo se va produciendo un apoderamiento de los directores y guionistas del texto clásico para dar una propia lectura, a veces contradictoria con el texto de origen y en otras superándolo en fuerza y comunicación. 
c) El propio concepto de clásico ha hecho que cada vez más se entienda este término como mucho más cercano a nuestra época, y de ese modo puede hoy parecernos tan clásico Don Quijote que Bodas de sangre o Luces de Bohemia. Por tanto, un análisis exhaustivo de la influencia de los clásicos literarios, más allá del teatro, nos produciría un listado de vértigo.

d) Las influencias que directores y guionistas han tenido de los clásicos de toda época a veces no son detectados con facilidad, pues precisamente su articulación al lenguaje cinematográfico produce sorprendentes mestizajes.

e) La industria cinematográfica tuvo que superar bastantes prejuicios con respecto a la adaptación de clásicos por una cierta idea extendida de que los clásicos son aburridos.

f) Pienso que si hubiera más osadía y riesgo en nuestro cine español, beber de los clásicos es una oportunidad de futuro, siempre y cuando no se hagan meras recreaciones arcaicas o coartadas culturalistas. 